УдК 613.955

DOI: $10.26435 /$ UC.V0I1(34).416

\author{
Е.Ю. Сероштан, Б.А. Безкаравайный
}

ГУ ЛНР «Луганский государственный медицинский университет имени Святителя Луки», Луганск

\title{
ОСОБЕННОСТИ ФИЗИЧЕСКОГО ЗДОРОВЬЯ ДЕТЕЙ МЛАДШЕГО ШКОЛЬНОГО ВОЗРАСТА С НАРУШЕНИЕМ ОСАНКИ
}

Процессы роста и развития - общебиологические свойства живой материи. Преобразование наследственной информации в систему жизненных связей фенотипа с окружающей средой является сутью индивидуального развития. Изучение особенностей роста и развития детей в меняющихся социально-экономических условиях относится к числу ключевых проблем профилактической медицины на современном этапе [1-3]. С началом систематического обучения в деятельности детей преобладающим становится статический компонент. Вместе с тем статическая выносливость у детей младшего школьного возраста невелика, утомление организма развивается относительно быстро, что связано с возрастными особенностями двигательного анализатора. В связи с этим нарушение осанки является одним из наиболее распространенных состояний у детей школьного возраста [4-6]. Возникшие нарушения опорно-двигательного аппарата создают благоприятные условия для возникновения ряда других функциональных и морфологических расстройств здоровья в детском возрасте, а впоследствии оказывают негативное влияние на течение многих заболеваний по мере взросления.

В литературе недостаточно освещены вопросы состояния физического развития учащихся начальной школы с нарушением осанки. Последнее диктует необходимость более глубокого изучения данной проблемы методом скринингового обследования этих детей.

\section{ЦЕЛЬРАБОТЫ}

Дать комплексную оценку морфофункционального развития детей младшего школьного возраста с нарушением осанки.

\section{МАТЕРИАЛ И МЕТОДЫ}

Для решения поставленной задачи нами было обследовано 129 первоклассников. Из них выявлено 87 детей (40 мальчиков, 47 девочек) с нарушением осанки. Биологический возраст де- тей оценивали методом темпового соматотипа (сумма центильных интервалов для массы тела, длины тела и окружности грудной клетки). Скрининговая оценка физического развития предусматривала использование двух показателей - длины тела и индекса Кетле-2 по соответствующим центильным шкалам. Гармоничность морфофункционального состояния оценивали по совокупности следующих параметров: пропорциональности развития по масса-ростовому индексу, функциональному состоянию (жизненная емкость легких - ЖЕЛ, динамометрия), гемодинамическим показателям - систолическое (АДс) и диастолическое (АДд) артериальное давление, частота сердечных сокращений (ЧСС) [7]. Оценка уровня и степени гармоничности физического развития проведена на основе метода перцентилей. Расчет информативных индексов, характеризующих морфофункциональное состояние организма (жизненный индекс, индекс Робинсон), выполнен по индивидуальным исходным показателям антропометрии и гемодинамики [4].

Статистическую обработку данных проводили с использованием программного обеспечения Statistica 10.0. Соответствие анализируемых параметров закону нормального распределения оценивали по значениям тестов КолмогороваСмирнова, Лиллиефорса и $\mathrm{W}$-критерия ШапироУилка. Так как в большинстве случаев распределение не соответствовало закону нормального распределения, данные представлены в виде количества наблюдений в группе, медианы и интерквартильного размаха. Оценку статистической значимости различий показателей в сравниваемых группах проводили с использованием непараметрического критерия для независимых групп - рангового критерия Манна-Уитни, для зависимых групп - Т-критерия Уилкоксона.

(c) Е.Ю. Сероштан, Б.А. Безкаравайный, 2020

(c) Университетская Клиника, 2020 


\section{РЕЗУЛЬТАТЫ И ОБСУЖДЕНИЕ}

При определении биологического возраста учащихся было выявлено 44 (50,6 \%) школьника с мезосоматическим типом темпа роста. Из 40 мальчиков и 47 девочек мезосоматический тип имел место у 50,0 \% и 51,1 \%, соответственно. Ускоренный темп развития был отмечен у 34 (39,1 \%) детей (32,5 \% мальчиков, 44,7 \% девочек). Микросоматический темповый соматотип констатирован у 9 (10,3 \%) учащихся $(17,5 \%$ мальчиков, 4,2 \% девочек).

Нормальное физическое развитие имели 44 (50,6 \%) первоклассника (45,0 \% мальчиков, 55,3 \% девочек). С повышенной и высокой массой тела было выявлено 12 (13,8 \%) детей (7,5 \% мальчиков и 19,2\% девочек), со сниженной и низкой массой тела - 11 (12,7 \%) (20,0 \% мальчиков и 6,4 \% девочек), с высокой длиной тела 18 (20,7 \%) (19,1 \% девочек и 22,5 \% мальчиков), с низким ростом - 2 (2,2 \%) ребенка (5,0 \% мальчиков).

Анализ масса-ростового индекса Кетле-2 показал, что 36 (41,4 \%) детей имеют достаточное питание. Пограничное питание имело место у 28 (32,2 \%) школьников. Пограничное питание ниже среднего и выше среднего было выявлено в одинаковом количестве у 14 (16,1 \%) детей. Мальчиков с пограничным питанием ниже среднего было 15,0 \%, девочек - 14,9\%, в то время как выше среднего - 14,9 \% девочек и 17,5 \% мальчиков. Нарушение питания наблюдалось у 23 (26,4 \%) первоклассников. Очень низкое питание имели 5 (5,8 \%) учащихся (5,0 \% мальчиков, 6,4 \% девочек), низкое - 6 (6,9 \%) (10,0 \% мальчиков и 4,3 \% девочек), очень высокое - 7 (8,1 \%) $(12,5$ \% мальчиков и 4,3 \% девочек) и высокое питание - 5 (5,8 \%) детей (6,4 \% девочек и 5,0 \% мальчиков). Установленный средний показатель индекса Кетле-2 - у мальчиков 15.36 (13.437-16.667) и у девочек 15.419 (13.923-16.518) - был близок по значению и не имел статистически достоверной разницы ( $>>0,05)$.

Установлено, что силовые показатели кистей рук у 21 (24,1 \%) обследованного первоклассника соответствовали возрастной норме, у 66 (75,9\%) показатели были низкие. У мальчиков сила правой кисти 7,1 (18-1) и левой 4,9 (15-1) статистически выше ( $\mathrm{p}=0,03)$, чем у девочек - 3,4 (10-1) и 2,3 (8-1).

Согласно результатам динамометрии, 69 (79,3 \%) первоклассников имели низкий уровень физического здоровья (90,0 \% мальчиков, 70,2 \% девочек), в то время как средний уровень был отмечен у 2 детей (2,3 \%) (2,5 \% мальчиков и $2,1 \%$ девочек). Уровень развития ниже среднего по индексу силы кисти имели 8 (9,3%) учащих- ся (2,5 \% мальчиков, 14,9 \% девочек). Состояние физического здоровья выше среднего было у 6 (6,9 \%) школьников (5,0 \% мальчиков, 8,5 \% девочек). С высоким результатом уровня здоровья выявлено 2 (2,3 \%) девочки.

С 6,5 лет у детей начинают выявляться гендерные различия в показателях ЖЕЛ. Полученные индивидуальные показатели ЖЕЛ сопоставляли с долженствующими. Установлено, что у 66 (75,9 \%) первоклассников фактическая величина ЖЕЛ была ниже долженствующей нормы, что позволило расценить это как уменьшение вентиляционной и, соответственно, функционально-энергетической возможности. У мальчиков средняя величина ЖЕЛ умеренно снижена от долженствующей на 16,3 \%. У девочек фиксировано снижение показателей ЖЕЛ на 9,7 \%, что соответствует колебаниям в пределах возрастных нормативов.

Анализ индивидуальных величин жизненного индекса у детей младшего школьного возраста позволил определить уровень их соматического здоровья. У 12 (13,8 \%) первоклассников уровень соматического здоровья был низкий (27,5 \% мальчики и 2,1 \% девочки), у 7 (8,1 \%) - ниже среднего (7,5 \% мальчики, 8,5 \% девочки). Средний показатель соматического здоровья выявлен у 16 (18,4 \%) детей (12,5 \% мальчики, 23,4 \% девочки). В то же время уровень соматического здоровья выше среднего был у 13 $(14,9 \%)$ школьников (12,5 \% мальчики, 17,0 \% девочки), высокие показатели - у 39 (44,8 \%) детей (40,0 \% мальчики, 48,9 \% девочки).

По средним показателям ЧСС, равной 100 (96-100) ударам в минуту, функциональная активность системы кровообращения в условиях относительного физиологического покоя у первоклассников соответствовала верхней границе возрастной нормы. Выявленные средние значения АДс у девочек - 100 (96-100) мм рт. ст., у мальчиков - 102 (100-108) мм рт.ст. и АДд у девочек - 57 (50-63) мм рт. ст., 62 (60-67) мм рт. ст. у мальчиков соответствовали возрастной норме.

Расчет показателей индекса Робинсона выявил, что средний уровень систолической активности миокарда и его адаптационный потенциал соответствовали низкому уровню физического здоровья у 16 (18,4 \%) первоклассников (15,0 \% мальчиков, 21,3 \% девочек). Адаптационный потенциал сердечно-сосудистой системы был ниже среднего у 29 (33,3 \%) детей (37,5 \% мальчиков, 29,8 \% девочек), средний - у 27 (31,0 \%) школьников (30,0 \% мальчиков, 31,9 \% девочек), выше среднего - у 14 (16,1 \%) учащихся (17,5 \% мальчиков, 14,9 \% девочек) и высокий - у 1 (1,2 \%) ребенка. 


\section{В Ы В 0 д Ы}

1. Биологическому возрасту не соответствовало 49,4 \% обследованных первоклассников с нарушением осанки.

2. Центильная оценка длинны тела и индекса Кетле-2 позволила установить, что 50,6 \% первоклассников имеют нормальное физическое развитие.

3. Отклонение в физическом развитии имели 49,4 \% обследованных школьников. У девочек повышенная и высокая масса тела, высокая длина встречались одинаково часто. У мальчиков преобладали высокая длина, сниженная и низкая масса тела.

4. Сопоставление параметров пропорционального развития по индексу массы тела, функционального состояния (ЖЕЛ, динамометрия), гемодинамических показателей (ЧСС, СДд, АДд) выявило, что 22,4 \% детей характеризовались гармоничным морфофункциональным состоянием организма.

5. Достаточное питание отмечено у 43,0 \% учащихся первых классов. Высокое, очень высокое и пограничное питание выше среднего установлено у 35,0 \% мальчиков. Девочки в равных отношениях имели все типы нарушения питания.

6. По индивидуальным индексам силы кисти у 92,5 \% мальчиков и 85,1 \% девочек, а также жизненного индекса у 35,0 \% мальчиков и у 10,7 \% девочек уровень физического здоровья был расценен как низкий и ниже среднего.

7. Уровень ЧСС, АДс, АДд в условиях относительного физического покоя у первоклассников с нарушением осанки соответствовал возрастной норме.

8. У 52,5\% мальчиков и 51,1 \% девочек уровень адаптационного потенциала сердечнососудистой системы был ниже среднего.

\section{Е.Ю. Сероштан, Б.А. Безкаравайный}

ГУ ЛНР «Луганский государственный медицинский университет имени Святителя Луки», Луганск

\section{ОСОБЕННОСТИ ФИЗИЧЕСКОГО ЗДОРОВЬЯ ДЕТЕЙ МЛАДШЕГО ШКОЛЬНОГО ВОЗРАСТА С НАРУШЕНИЕМ ОСАНКИ}

Цель работы. Дать комплексную оценку морфофункционального развития детей младшего школьного возраста с нарушением осанки.

Материалы и методы. Обследовано 87 первоклассников. Биологический возраст оценивали методом темпового соматотипа. Оценку физического развития осуществляли по центильным шкалам длины тела и индекса Кетле-2. Гармоничность морфофункционального состояния оценивали по совокупности следующих параметров: пропорциональности развития по индексу Кетле-2, функциональному состоянию, гемодинамическим показателям.

Результаты работы. При определении биологического возраста учащихся было выявлено 44 (50,6 \%) школьника с мезосоматическим типом темпа роста. Ускоренный темп развития был отмечен у 34 (39,1 \%). Микросоматический соматотип констатирован у 9 $(10,4 \%)$ учащихся.

Анализ индекса Кетле-2 показал, что 36 (41,4 \%) детей имели достаточное питание, 28 (32,2\%) - пограничное, 23 (26,4 \%) первоклассника - нарушение питания.

Силовые показатели кистей рук у 21 (24,1 \%) школьника соответствовали возрастной норме, у 66 $(75,9 \%)$ показатели были низкие. Установлено, что у 66 (75,9 \%) детей фактическая величина жизненной емкости легких была ниже долженствующей нормы. По средним показателям частоты сердечных сокращений, артериального давления функциональная ак- тивность системы кровообращения у учащихся соответствовала верхней границе возрастной нормы.

Выводы.

Биологическому возрасту не соответствовало 49,4 \% первоклассников с нарушением осанки. Центильная оценка длины тела и индекса Кетле-2 позволила установить, что 50,6 \% первоклассников имеют нормальное физическое развитие. Отклонение в физическом развитии имели 49,4 \% обследованных школьников. Сопоставление параметров пропорционального развития по индексу массы тела, функционального состояния и гемодинамических показателей выявило, что 22,4 \% детей характеризовались гармоничным морфофункциональным состоянием организма. Достаточное питание отмечено у 41,4 \% учащихся первых классов. По индивидуальным индексам силы кисти у 88,5 \% первоклассников, а также жизненного индекса у 21,9 \% детей уровень физического здоровья был расценен как низкий и ниже среднего. Уровень частоты сердечных сокращений, артериального давления в условиях относительного физического покоя у первоклассников с нарушением осанки соответствовал возрастной норме. У 51,7 \% детей уровень адаптационного потенциала сердечно-сосудистой системы был ниже среднего.

Ключевые слова: младший школьный возраст, биологический возраст, физическое развитие, гармоничность морфофункционального состояния. 


\section{O.Y. Syeroshtan, B.A. Bezkaravaynyy}

\section{SI LPR «St. Luke Lugansk State Medical University», Lugansk}

\section{FEATURES OF THE PHYSICAL HEALTH OF PRIMARY SCHOOL CHILDREN WITH IMPAIRED POSTURE}

Objective. To evaluate the morphofunctional development of primary school children with impaired posture.

Materials and methods. 87 first-graders were examined. Biological age was evaluated by the method of tempo somatotype. Physical development was evaluated on centile scales of body length and Quetelet-2 index. The harmony of the morphofunctional state was evaluated by the combination of the following parameters - the proportionality of development according to the Ketle-2 index, functional state and hemodynamic indicators.

Results and discussion. When determining the biological age of pupils $44(50,6 \%)$ schoolchildren with a mesosomatic type of growth rate were identified. 34 (39,1 $\%)$ had an accelerated pace of development. Microsomatic somatotype was found in 9 (10,3 \%) students.

The analysis of the Ketle- 2 index showed that $36(41,4$ \%) children had adequate nutrition, 28 (32,2 \%) had borderline nutrition, 23 (26,4\%) of the first-graders had malnutrition.

The strength indicators of the hands in $21(24,1 \%)$ children corresponded to the age norm, and in $66(75,9$ $\%)$ the indicators were low. It was found that in $66(75,9$ $\%$ ) children the actual value of lung capacity was lower. According to average indicators of heart rate and blood pressure, the functional activity of the circulatory system in children corresponded to the upper limit of the age norm.

Conclusions.

$49,4 \%$ of first-graders with impaired posture did not correspond to the biological age. A consistent assessment of body length and the Ketle- 2 index allowed us to establish that $50,6 \%$ of first-graders have normal physical development. A comparison of the parameters of proportional development in terms of body mass index, functional state and hemodynamic parameters revealed that $22,4 \%$ of children were characterized by a harmonious morphofunctional state of the body. $41,4 \%$ of first-grade children had adequate nutrition. The low and below average physical health level were determined in $88,5 \%$ of the first-graders according to individual hand strength indices and in $21,9 \%$ of children according to life index children. The level of heart rate, blood pressure corresponded to the age norm in first-graders with impaired posture in conditions of relative physical rest. The level of adaptive capacity of the cardiovascular system was below average in $51,7 \%$ of children.

Key words: primary school age, biological age, physical development, harmony of morphofunctional state.

\section{ЛИТЕРАТУРА}

1. Богомолова Е.С., Кузмичева Ю.Г., Бадеева Т.В., Ашина М.В., Косюга С.Ю., Киселева А.С. Физическое развитие современных школьников Нижнего Новгорода. Медицинский альманах. 2012; 3 (22): 193-198.

2. Абрамишвили Г.А. Современный взгляд на проблемы физического воспитания учащихся младшего школьного возраста. Ученые записки. 2014; 11 (117): 7-12.

3. Погребняк Т.А., Сергеева М.С. Физическое развитие как показатель уровня адаптации и здоровья первоклассников. Научный результат. 2015; 3: 33-42.

4. Зеновский И.С., Суханов С.Г. Сравнительная оценка показателей физических качеств здоровых детей и детей с нарушением осанки младшего школьного возраста. Материалы IX Международной студенческой научной конференции «Студенческий научный форум» URL: https://scienceforum.ru/2017/article/2017034260 (дата обращения: 16.12.2019).

5. Ахмадулина Х.М., Ахмадулина У.З., Горбаткова Е.Ю. Двигательная активность учащихся младшего школьного возраста (в рамках спортивно-оздоровительного проекта «Здоровое поколение - сильный регион»). Вестник ВЭГУ. 2018; 4 (96): 7-14.

6. Тамбовцева Р.В. Физиологические основы развития двигательных качеств. Новые исследования. 2011; 29 (1): 5-14.

7. Богомолова Е.С. (ред.), Кузмичев Ю.Г., Матвеева Н.А.. Методы изучения и оценки физического развития детей и подростков. Н. Новгород: Нижегородской государственная медицинской академии; 2018. 92.

\section{REFERENCES}

1. Bogomolova E.S., Kuzmicheva Yu.G., Badeeva T.V., Ashina M.V., Kosyuga S.Yu., Kiseleva A.S.. Fizicheskoe razvitie sovremennykh shkol'nikov Nizhnego Novgoroda. Meditsinskii al'manakh. 2012; 3 (22): 193-198 (in Russian).

2. Abramishvili G.A. Sovremennyi vzglyad na problemy fizicheskogo vospitaniya uchashchikhsya mladshego shkol'nogo vozrasta. Uchenye zapiski. Uchenye zapiski. 2014; 11 (117): 7-12 (in Russian).

3. Pogrebnyak T.A., Sergeeva M.S. Fizicheskoe razvitie kak pokazatel' urovnya adaptatsii i zdorov'ya pervoklassnikov. Nauchnyi rezul'tat. 2015; 3: 33-42 (in Russian).

4. Zenovskii I.S., Sukhanov S.G. Sravnitel'naya otsenka pokazatelei fizicheskikh kachestv zdorovykh detei i detei s narusheniem osanki mladshego shkol'nogo vozrasta. Materialy IX Mezhdunarodnoi studencheskoi nauchnoi konferentsii «Studencheskii nauchnyi forum» Materials of IX International student scientific conference « Student scientific forum» Available at: https://scienceforum.ru/2017/ article/2017034260 (accessed: 16.12.2019) (in Russian).

5. Akhmadulina Kh.M., Akhmadulina U.Z., Gorbatkova E.Yu. Dvigatel'naya aktivnost' uchashchikhsya mladshego shkol'nogo vozrasta (v ramkakh sportivnoozdorovitel'nogo proekta «Zdorovoe pokolenie - sil'nyi region») Vestnik VEGU. 2018; 4(96): 7-14 (in Russian).

6. Tambovtseva R.V. Fiziologicheskie osnovy razvitiya dvigatel'nykh kachestv. Novye issledovaniya. 2011; 29 (1): 5-14 (in Russian).

7. Bogomolova E.S. (eds.), Kuzmichev Yu.G., Matveeva N.A.. Metody izucheniya i otsenki fizicheskogo razvitiya detei i podrostkov. N. Novgorod: Nizhegorodskoi gosudarstvennaya meditsinskoi akademii; 2018.92 (in Russian). 